\title{
The Preparation of Students of the Pedagogical College for Professional Activities with Children with Severe Speech Disorders
}

\author{
Natalia Berdnikova ${ }^{1,}{ }^{*}$, Natalia Abashina ${ }^{2}$, Elena Klimkina ${ }^{2}$, and Nadezhda Manokhina ${ }^{2}$ \\ ${ }^{1}$ Municipal Budgetary Preschool Educational Institution No. 50, Rostov-on-Don, 38 Petrovskaya Str., \\ 344022 Rostov-on-Don, Russia \\ ${ }^{2}$ Don State Technical University, 1 Gagarina Pl, 344003 Rostov-on-Don, Russia
}

\begin{abstract}
The article presents the theoretical and methodological aspect of the problem of preparing students of the pedagogical college for professional activities with children with severe speech disorders. The working program of the academic discipline "Organization and content of speech therapy support for children with severe speech disorders", specialty 44.02.01 Preschool education, describes the practice-oriented pedagogical technologies for including students in working with children with speech disorders.
\end{abstract}

\section{Introduction}

The relevance of the research problem is due to the fact that in the current situation of education development, there is an urgent need to train teachers of preschool educational institutions who are able to work in changing social and economic conditions, oriented in the needs of society, and also have high competence in their professional field. The teacher must have developed professionally significant personal qualities, possess psychological and pedagogical technologies for working with children with both a conditional norm in development and with children with speech disorders, and be able to reflect on their own pedagogical activities. The teacher of a preschool educational institution is responsible for the chosen goals, tasks, content, methods of teaching and upbringing. Having a professional mindset, a teacher should be able to predict events and actions, know how to analyze professional situations, make professional decisions, and flexibly build a correctional and pedagogical process.

The problem of readiness of students of secondary and higher educational institutions for pedagogical activity in different historical periods was studied by E. E. Artemova, L. A. Tishina, O. S. Glukhovoedova, M. A. Adilzhanova, etc. [1]

Readiness for professional activity is interpreted by scientists as a complex personal education, which includes the ability to think, design the educational process, as well as the ability to practically act. In the studies of T. V. Amosov, M. I. Dyachenko, L. A. Kandybovich, S. L. Kandybovich, the concept of readiness for professional activity is considered in the aspect of personal-activity interaction, as a special manifestation of all

\footnotetext{
* Corresponding author: PlatohinaN@yandex.ru
} 
aspects of the personality, the maximum capacity of a person to effectively perform their functions [2-3].

Problems of formation of the correctional and pedagogical assistance to children with developmental disabilities and ways of its improvement are discussed in the works of I.A. Yudina; program-targeted foundations for managing the development of the professional competence of future educators in the system of corrective and developing education in the study of M.I. Abramova; analysis of the psychological conditions of improving the professional competence of a speech therapist in the works of I.A. Yurlovsky, F.K. Tubeeva; The description of the results of the experimental study of the readiness of future teachers to work with children with severe speech impairments is presented in the writings of E.V. Vasilyeva. the technologies of forming the professional competence of future teachers are described in the works of S.A. Dudnikova, N.A. Platokhina, A.V. Isayev, V.G. Ignatovich.

We consider professional readiness as the beginning of a professional career and the beginning of the process of sustainable self-identification in the profession by systematizing the acquired knowledge and building a picture of professional reality. The analysis of foreign psychological and pedagogical sources showed that students in the learning process need to: -to master social skills, to understand the values and lifestyle associated with this profession. (M.K. Asanaliev, M. Buravoy, H.M. Hajikurbanova E. Liliana Danciu, C. Yunsong, F. Xiaoguang) [10-14];

-to have psychological training to work in educational institutions of different types (R. Ponce de Leon, A.C. Kay, M. Seligman, J.G. Marqués, C.P. Mapas, D. Jones, D. Rahal, V. Huynh, S. Cole) [15- 19],

-to be able to manage conflict situations (C.A.Parker, K Bickmore) [20],

-to master the physiological foundations for understanding, studying and justifying somatophysiological changes in the body (L. Sanci) [21],

-to have pedagogical training that allows future specialists to properly organize psychological and educational support for children (C.G. Alemán, A.P. León Urquijoa, E. Risco-del-Valleb, C.A. Salvoc) [22-23]

-to master fundamental knowledge (Y.M. Gibadullina) [24]

-to have basic medical knowledge about helping children with normal development and disabilities (S. P. Bach, P. P. Hogh, A. J. Hviid) [25].

It should be noted that the research of these authors aimed primarily at lighting theoretical approaches to the essence and content of training, the formation of the personality of future educators, to develop in students the necessary pedagogical competences, at the same time, it should be noted that the process of training future teachers to work with preschool children with severe speech disorders in the system of secondary vocational education neglected. In preschool educational institutions, there is a shortage of teachers who are able to work professionally with children with problems in speech development, including children with severe speech disorders.

Thus, the analysis of foreign and Russian studies allows us to formulate the following contradictions:

- between the traditional model of educator training, where the knowledge-educational paradigm of education prevails, and the real dynamic life of preschool educational institutions, which requires a teacher capable of solving pedagogical problems of various complexity, including in the process of working with children with speech disorders;

- the need to carry out correctional and pedagogical work with children with speech disorders by specially trained teachers and insufficiently clearly formulated structure, content of their readiness for this type of activity;

- the special role of professional disciplines in the formation of students ' readiness for professional activities with preschool children and their insufficient focus on the specifics of working with children with severe speech disorders. 
The methodological basis of the research is based on the following scientific approaches: a competence-based approach to training specialists in the field of special education (I. A. Zimnaya, G. S. Trofimova, etc.) [26-27]; an active approach aims at using interactive teaching methods and techniques in the learning process (V. P. Bugrin, N. V. Borisova, M. S. Sidorin, E. V. Chukhaev, V. G. Ignatvich, S. A. Dudnikova, N. A. Platokhina, A.V. Isaev, etc.) [[8;9]; a systematic approach allows you to design didactic system of training specialists in the field of special (defectological) education (N. V. Kuzmina, T. L. Korzhenevich, V. V. .. Yudin, etc.) [28-30].

\section{Results of the research.}

The analysis of psychological and pedagogical and special scientific literature, the practice of pedagogical colleges allowed us to formulate the purpose of the study: to identify the levels of readiness of students of pedagogical colleges for professional activities with children with severe speech disorders.

In accordance with the goal, the following tasks were defined:

a) Methodical:

- to identify the criteria of readiness of students of the pedagogical college for professional activity with children with severe speech disorders and to describe their qualitative characteristics;

- to determine the diagnostic tools for studying the readiness of students of the pedagogical college for professional activity with children with severe speech disorders

b) Empirical:

- to conduct an empirical study of the readiness of pedagogical college students to work professionally with children with severe speech disorders;

- conduct a comparative analysis of the obtained results;

- interpretation of the data obtained on their basis to draw conclusions about the peculiarities of the readiness of students of the pedagogical college to work with children with severe speech disorders.

The experimental work was carried out based on the Don Pedagogical College, Rostovon-Don. The study involved 20 students of the 3rd year, groups D-3A., D-3B studying in the specialty: 44.02.01. preschool education.

In solving the methodical problem of the study, we systematized and adapted to the study the criteria for the readiness of students of the pedagogical college for professional activity with children with severe speech disorders and described their qualitative characteristics (according to E. E. Vasilyeva) [7].

Table 1. Criteria and indicators of readiness of students of the pedagogical college for professional activity with preschool children with severe speech disorders

\begin{tabular}{|l|l|}
\hline Evaluation criteria: & Indicators \\
\hline Content criterion & the future teachers of preschool educational institutions have \\
& theoretical knowledge on the problem of speech \\
development and correction (ontogeny of speech & development of preschool children, psychological and \\
pedagogical features of the development of children with \\
speech disorders, classification of speech disorders, \\
classification of severe speech disorders, causes of speech \\
disorders, regulatory and legal bases for teaching children \\
with disabilities, ideas about technologies for supporting and \\
correcting speech), ensuring that the teacher determines the
\end{tabular}




\begin{tabular}{|l|l|}
\hline \multirow{7}{*}{ Activity criterion } & $\begin{array}{l}\text { content of their own professional activities, awareness of } \\
\text { working with children with speech disorders; }\end{array}$ \\
\hline $\begin{array}{l}\text { the presence of future teachers of preschool educational } \\
\text { institutions of professional skills tested in action and } \\
\text { mastered as the most effective in the process of speech } \\
\text { correction of preschool children with severe speech } \\
\text { disorders (technology of psychological and pedagogical } \\
\text { support, speech correction; educational and educational } \\
\text { programs of speech correction, author's technologies of } \\
\text { speech development of preschool children, social } \\
\text { partnership of preschool educational institutions and } \\
\text { families in the process of correction and support of speech } \\
\text { development of children; designing speech development } \\
\text { activities for preschoolers with speech disorders); }\end{array}$ \\
\hline Personality criterion & $\begin{array}{l}\text { the presence of future teachers of preschool educational } \\
\text { institutions of professional and personal qualities that } \\
\text { determine the orientation and position of the teacher as a } \\
\text { subject of activity in the process of correcting and } \\
\text { developing the speech of children with speech disorders } \\
\text { (tolerance, differentiated approach to children and their } \\
\text { parents, prevention of deviant behavior of the child). }\end{array}$ \\
\hline
\end{tabular}

In solving the second problem of the ascertaining stage of the experiment, methods of evaluating students of the pedagogical college for professional activity with preschool children with severe speech disorders were systematized. During the experiment, we developed:

- questionnaires for students "Theory and practice of development and correction of speech of preschool age" (the purpose of the questionnaire: to identify the level of competence of students on the problem of development and correction of speech of preschool age).

- questionnaire "Analysis of reports and practice diaries" (purpose: analysis of students ' difficulties in the process of organizing interaction with children with normal development and with children with speech disorders)

- criteria for analyzing the observation of student's activities in practice in the process of educational and correctional work with children with speech disorders" (purpose: to analyze the nature of students ' interaction with children with speech disorders, the organization of educational and educational work).

Analysis of the results of the study showed that students in the experimental group were not able to fully demonstrate theoretical knowledge on the development and correction of speech of preschool children (ideas about the psycho-pedagogical features of development of children with speech disorders, the classification of speech disorders, the causes of speech disorders, etc.), students are not formed professional skills related to the maintenance and correction of preschool children (technology, programming, social partnership, design); the students were unable to fully demonstrate the professional and personal qualities necessary 
to work with children with speech disorders (differentiated approach to children, prevention of deviant behavior of the child).

A quantitative analysis of the results showed that $21.42 \%$ of students had a critical (unacceptable) level of professional competence, $64.78 \%$ of students had a basic level of professional competence, $10.34 \%$ of students had an intermediate level of competence, and $3.46 \%$ of respondents had a professional level of competence.

The obtained data allowed us to develop a working program of the academic discipline "Organization and content of speech therapy support for children with severe speech disorders", specialty 44.02.01 Preschool education. The program is compiled in accordance with the requirements of the Federal State Educational Standard of Secondary Vocational Education.

The purpose of mastering the discipline is to form professional competence of future teachers of preschool educational institutions in the field of organizing speech therapy support for children with severe speech disorders

The tasks of mastering the program:

1. To expand the ideas of future teachers of preschool educational organizations about the theoretical foundations of the development and correction of speech of children with severe speech disorders (ontogeny of speech development of preschool children, psychological and pedagogical features of the development of children with speech disorders, classification of speech disorders, classification of severe speech disorders, causes of speech disorders, regulatory and legal foundations of teaching children with disabilities, ideas about technologies for supporting and correcting speech, etc.).

2. Systematize the ideas of future teachers about the planning and organization of the process of development and correction of speech of children with severe speech disorders (drawing up a work program for children with severe speech disorders, a perspective-thematic work plan, an individual program for accompanying children with severe speech disorders).

3. To form the ideas of future teachers about effective technologies for the development and correction of speech of children with severe speech disorders (modeling, story-role-playing games, correctional exercises, etc.).

4. Formation of motivation, psychological readiness to work with children with health problems.

5. To develop professional skills and abilities of future teachers in the process of implementing programs, technologies for the development and correction of speech of children with severe speech disorders, interaction with specialists and parents.

6. To form a tolerant attitude towards people with disabilities among future teachers.

The laboriousness of the discipline is 72 hours, including: mandatory classroom load of 48 hours; independent work of students 24 hours, intermediate certification - credit.

The process of mastering the discipline is aimed at the formation of the following competencies of students: to organize their own activities, determine methods for solving professional tasks, evaluate their effectiveness and quality; to plan various activities and communication of children during the day; to develop methodological materials based on approximate ones, taking into account the peculiarities of age, group and individual pupils.

To master the discipline "Organization and content of speech therapy support for children with severe speech disorders", you need knowledge from the previous disciplines: "Fundamentals of Physiology and Hygiene", "Fundamentals of General Psychology", "Fundamentals of Special Pedagogy", "Fundamentals of research activities in preschool educational institutions".

As a result of mastering the program, teachers should:

- know: features of the development and correction of speech in children with severe speech disorders, the causes of speech disorders, the legal framework for teaching children with 
disabilities, programs, technologies for supporting and correcting speech, the organization of a correctional and developmental environment;

- be able to: test technologies for supporting and correcting speech, organizing a correctional and developmental environment with children with severe speech disorders, methods for solving professional tasks, and evaluate their effectiveness and quality;

- possess: professional skills and abilities in the process of implementing technologies for supporting and correcting the speech of children with severe speech disorders in a preschool educational organization.

The content of the discipline "Organization and content of speech therapy support for children with severe speech disorders" includes the following sections:

Section 1. "Theoretical foundations of speech development and correction in children with severe speech disorders".

Section 2. "Organization of activities in a preschool educational institution aimed at the development and correction of speech of children with severe speech disorders".

The most effective technologies for mastering the discipline were:

- teaching and research tasks (to make the comparison table on the topic "Classification of severe speech disorders", "Technology development and correction of speech of children with severe speech disorders");

- socio-game tasks (students were asked to imagine themselves in roles such as the Minister of education and to offer their solutions to pressing problems help children with limited opportunities of health);

- practice-oriented task (completing an essay on one of the proposed topics "A child with severe speech disorders: problems and solutions", "Prevention of speech disorders in preschoolers", "Game methods and techniques for correcting children's speech", "Communication with peers of children with speech disorders: problems and solutions", etc.); - social and creative task (within 10 days, students prepare to participate in the competitions "Effective methods and techniques for speech development of children with speech disorders"; for the best methodological development "Game technologies for speech development of children with severe speech disorders", etc.);

- project task (students were asked to develop an author's project on one of the topics "Individual program for accompanying a child with speech disorders", " Interaction with specialists in the process of development, correction of children's speech, etc.);

- creative task (students were asked to prepare a presentation about one of the topics "Ontogeny of speech development of preschoolers", "Software for the development and correction of children's speech", "Methods and techniques for expanding and activating the speech reserve of children with speech disorders", "Methods and techniques for developing the ability to apply the formed skills of coherent speech in speech situations", etc.); preparation of the summary of direct educational activities for the kids with problem of speech development and training: children with severe speech disorders (plan structure: topic, age group, goal, tasks, materials (demonstration and handout), preliminary work, methods and techniques, progress, summing up, reflection); create a card file of technologies for speech therapy support of persons with severe speech disorders: diagnostic techniques, game, project, communication, information technologies, the structure of the individual program of support for children with speech disorders; test tasks to consolidate the formed ideas on the discipline.

\section{Conclusion.}

Summing up the implementation of the academic discipline "Organization and content of speech therapy support for children with severe speech disorders", we concluded that the program contributed to the expansion of the ideas of future teachers of preschool educational 
organizations about the theoretical foundations of the development and correction of speech of children with severe speech disorders (ontogeny of speech development and training of preschool children, psychological and pedagogical features of the development of children with speech disorders, classification of speech disorders, classification of severe speech disorders, causes of speech disorders, regulatory and legal bases of teaching children with disabilities, ideas about technologies for supporting and correcting speech, etc.); systematization of the ideas about planning and organizing the process of developing and training children with severe speech disorders (drawing up a work program for children with speech disorders, a perspective-thematic work plan, an individual program for supporting children with speech disorders); about effective technologies for developing and correcting speech in children (modeling, story-role games, correctional exercises, etc.); development of professional skills and abilities of future teachers in the process of implementing programs, technologies for the development and correction of speech of children with speech disorders, interaction with specialists and parents; education of future teachers of a tolerant attitude to persons with disabilities, the formation of psychological readiness to work with children with disabilities.

The results of a repeated diagnostic study of the level of professional competence of students showed that $6.34 \%$ of respondents had a critical level of professional competence; $61.2 \%$ of students had a basic level of competence; $7.45 \%$ had an intermediate level of competence and $25.01 \%$ had a professional level of competence. The results obtained allowed us to conclude about a high level of efficiency to use.

\section{References}

1. E.E. Artemova, L.A. Tishina, O.S. Glukhovoedova, M.A. Adilzhanova, Psychological and pedagogical conditions for the formation of professional competencies among students of defectology faculties in the process of working with non-speaking children, 3, ISSN: 1992-6391 (Bulletin of the M. A. Sholokhov Moscow State University for the Humanities, 2013)

2. T. V. Amosova, Basic approaches to the definition of the concept of readiness for professional activity 9, ISSN: 1992-6057 (Bulletin of the Komi State Pedagogical Institute, 2011)

3. M.I. Dyachenko, The role and place of teaching methods in vocational training, Management and Law 4(49), 58-61 (Bulletin of the Ural Institute of Economics, 2019)

4. I.A. Yudina, Structural and functional model of professional development of a teacher in a virtual pedagogical event community and Letters in the Issue. Offline (The Emissia. Offline Letters): an electronic scientific journal, ART 1610 (St. Petersburg., 2011)

5. M. Yu. Abramova, Analysis to determine the professional readiness for the driver's activity 3, ISSN: 1813-145X (Yaroslavl Pedagogical Bulletin, 2012)

6. F.K. Tarbeeva, I. A. Orel, Especially teaching younger students with hearing impairments with the use of ICT, Economic and humanitarian research of the regions $\mathbf{3}$, 66-69 (2019)

7. E.E. Vasilyeva, Experimental study of students ' readiness to work with children with severe speech disorders, Yaroslavl Pedagogical Bulletin 4, ISSN: 1813-145X (2014).

8. N.A. Platokhina, V. G. Ignatovich, Modern educational technologies as a means of improving the quality of teacher training in higher educational institutions, In the collection: Improving the quality of teacher training: Problems. Innovative technologies. Experience. Collection of materials of the International Scientific and Practical Conference. Under the General editorship of J. H. Baskaeva, 344-350 (2019) 
9. S. A Dudnikova, N. A. Platokhina, A.V. Isaev, Technologies for the formation of professional competence of future teachers in the process of performing project tasks, Current issues of professional education, 3(8), 25-28 (2017)

10. M.K. Asanaliev, Technology of students' independent work organization and management, European Researcher 38(1-1), 80-8 (2013)

11. M. Buravoy, Facing an unequal world, Current Sociology 63(1), 5-34 (2015) DOI: 10.1177/0011392114564091

12. H. M. Hajikurbanova, Analysis of approaches to the classification of cases, World of Science, Culture, Education 3(40), 9-11 (2013)

13. E. Liliana Danciu, Procedia - Social and Behavioral Sciences 30, 2204-2209 (2011) doi:10.1016/j.sbspro.2011.10.429

14. C. Yunsong, F. Xiaoguang, Social sciences in china 3, 70-88 (2019) https://doi.org/10.1080/02529203.2019.1595063

15. R. Ponce de Leon, A.C. Kay, Current Opinion in Behavioral Sciences 34, 112-117 (2020) https://doi.org/10.1016/j.cobeha.2020.02.013

16. M. Seligman, Positive psychology: An introduction, Flow and the foundations of positive psychology, 279-298 (2014)

17. J.G. Marqués, C.P. Mapas, European Journal of Education and Psychology 1(10), 33-39 (2017) DOI: https://doi.org/10.30552/ejep.v10i1.130

18. D. Jones, Archives and Records: The Journal of the Archives and Records Association 1(36), 29-41 (2015) http://dx.doi.org/10.1080/23257962.2015.1010149

19. D. Rahal, V. Huynh, S. Cole, Developmental psychology 6, 1220-1232 (2020) https://doi.org/10.1037/dev0000919

20. C.A. Parker, K. Bickmore, Conflict Management and Dialogue with Diverse Students: Novice Teachers' Approaches and Concerns, Journal of Teaching and Learning 8(2) (2012)

21. L. Sanci, Journal of Adolescent Health 2(67), S1eS2 (2020) DOI: https://doi.org/10.1016/j.jadohealth.2020.05.017.

22. C.G. Alemán, Revista de la Educación Superior 46(182), 117-119 (2017) https://ru.scribd.com/document/360509640/Revista182-S1A2ES

23. A.P. León Urquijoa, E. Risco-del-Valleb, C.A. Salvoc, Revista de la Educación Superior 43(172), 123-144 (2014) DOI: 10.1016/j.resu.2015.03.012

24. Y.M. Gibadullina, Fundamental studies 10, 2253-2257 http://fundamentalresearch.ru/ru/article/view?id=35929

25. S. P. Bach, P. P. Hogh, A. J. Hviid, et al., Bmc public health bmc Public Health 20, 396 (2020) https://doi.org/10.1186/s12889-020-08509-8

26. I.A. Zimnyaya, Key competencies - a new paradigm of the result of education, Experiment and innovations in school 2 (2009)

27. G.S. Trofimova, Pedagogical communicative competence: theoretical and applied aspects, 114p. (Izhevsk: Udmurt University, 2012)

28. N.V. Kuzmina, Acmeological factors of the development of the communicative culture of a teacher of a military educational institution, Actual problems of the humanities and socio-economic sciences 11(8), 134-139 (2017)

29. T.L. Korzhenevich, Study and formation of professional competence in the future teacher-defectologist, News of the Volgograd State Pedagogical University, 4 (2009) 
30. V.V. Yudin, Technological approach in pedagogy, Digest: Pedagogical technologies in the conditions of modernization of education. Materials of the international scientific and practical conference 17-22 (2015) 